\title{
The Generation and Quantification of Resistance to Dimethomorph in Phytophthora infestans
}

J. M. Stein, Texas Agricultural Experiment Station, Bushland 79012, and W. W. Kirk, Department of Plant Pathology, Michigan State University, East Lansing 48824

\begin{abstract}
Stein, J. M., and Kirk, W. W. 2004. The generation and quantification of resistance to dimethomorph in Phytophthora infestans. Plant Dis. 88:930-934.

The generation of dimethomorph resistance in Phytophthora infestans was attempted using ethidium bromide/UV light mutagenesis and repeated culturing on dimethomorph-amended medium. Ethidium bromide/UV mutagenesis created two isolates of $P$. infestans with resistance factors for dimethomorph $>20$, i.e., the ratio of the $50 \%$ effective concentration $\left(\mathrm{EC}_{50}\right)$ of the mutant to that of the wild-type. With repeated culturing on dimethomorph-amended medium, the rate of growth ( $\mathrm{mm}$ diameter/day) increased until the tenth subculture for most $P$. infestans isolates. Resistance factors generated from repeated culturing were $<8$ for all isolates. For most isolates, the generation of dimethomorph resistance resulted in reduced growth rates on nonamended medium, regardless of the level of resistance or induction treatment. Additionally, the frequency of infection of leaf disks and whole tubers was significantly reduced in $>20 \%$ of the isolates repeatedly subcultured on dimethomorph-amended medium. Regardless of the induction treatment, reduced fitness was common for all $P$. infestans isolates, indicating a potential biological cost associated with dimethomorph resistance. Based on these results, the development of field resistance to dimethomorph in $P$. infestans is unlikely with the currently employed resistance management strategies.
\end{abstract}

Additional keywords: fungicide, late blight, Oomycete, Solanum tuberosum

Resistance to fungicides in fungal and Oomycete plant pathogens has become increasingly common following the release of systemic, single-mode-of-action fungicides in the 1960s (7). Field resistance to every major systemic fungicide class has occurred in at least one species of plant pathogenic fungi or Oomycetes $(19,23)$, leading to drastic shifts in fungicide programs for many pathosystems, such as potato late blight. The migration of phenylamide insensitive populations of Phytophthora infestans (Mont.) de Bary, the causal agent of potato and tomato late blight, from Mexico to the rest of North America (12) necessitated cultural control methods and crop protection strategies that relied primarily on protectant foliar fungicide applications (22). Concurrently, the agrichemical industry developed and released systemic fungicides with novel modes of action in an attempt to replace the phenylamides.

Dimethomorph, one of the fungicides released in response to phenylamide resistance, is a cinnamic acid derivative with a

Corresponding author: W. W. Kirk

E-mail: kirkw@msu.edu

Accepted for publication 18 April 2004.

Publication no. D-2004-0621-04R

(C) 2004 The American Phytopathological Society high specificity to certain members of the Peronosporaceae, including Phytophthora spp. (1). Cells of $P$. infestans lacking cell walls, such as zoospores and artificially generated protoplasts, were not affected by dimethomorph $(2,24)$, and it was concluded that dimethomorph disrupted cell wall formation by interfering with the molecular arrangement of cell wall components and not the inhibition of component synthesis (16).

Laboratory resistance to dimethomorph was generated with UV light mutagenesis in one isolate of $P$. parasitica (6) and with chemical mutagenesis in one isolate of $P$. capsici (26). In both cases, an approximate 20 -fold increase in the effective concentration required for a $50 \%$ reduction in colony diameter $\left(\mathrm{EC}_{50}\right)$ resulted. Virulence of dimethomorph resistant isolates of $P$. parasitica was found to be equal to, or less than, the wild-type. In addition, dimethomorph resistance in $P$. parasitica was stable in the absence of dimethomorph through several in vitro subcultures for 3 months. Conversely, attempts to generate resistance using mycelial selection in $P$. infestans and $P$. capsici resulted in small (less than twofold) decreases in sensitivity to dimethomorph (26). The use of only one culture of $P$. infestans and $P$. capsici in the latter experiment may have limited the results, as genetic variability was absent.

The objectives of this study were to (i) generate resistance in $P$. infestans to di- methomorph using mycelial adaptation or ethidium bromide/UV mutagenesis, (ii) quantify the level of resistance generated, and (iii) determine if resistance to dimethomorph in $P$. infestans results in reduced virulence on potato foliage and tubers.

\section{MATERIALS AND METHODS \\ Preparation of amended medium and} fungicide stock solutions. Experiments involving in vitro hyphal growth were performed on modified rye B agar $(2,5)$ consisting of the filtrate of pre-rinsed rye (Secale cereale L.) seed (100.0 g/liter) boiled for $1 \mathrm{~h}$, deionized (d) $\mathrm{H}_{2} \mathrm{O}$ added to a final volume of 1.0 liter, glucose (8.0 $\mathrm{g} /$ liter $), \quad \beta$-sitosterol (0.05 g/liter), and Bacto agar (15.0 g/liter). All plates for each subculture on dimethomorphamended medium, or run of the sensitivity assay were prepared from the same batch in order to limit variability.

Dimethomorph (BASF Corp., Research Triangle Park, NC) 100X stock solutions were prepared by dissolving technical grade (95\% active) dimethomorph into $95 \%$ ethanol and performing serial dilutions as required in $95 \%$ ethanol. The stock solutions were added to molten medium at $10 \mathrm{ml} /$ liter when the temperature was cooled to approximately $55^{\circ} \mathrm{C}$ in a water bath. Fungicide solutions were passed through a $0.22-\mu \mathrm{m}$ syringe-driven filter (Millipore Corp., Bedford, MA) to sterilize. Medium for control plates received 10 $\mathrm{ml}$ of filter-sterilized ethanol per liter.

Resistance generation: mycelial selection. The wild-type of each isolate used in this study had been previously characterized (24) for mating type, genotype (11), and physiological race (3), was subcultured twice following re-isolation from inoculated potato tuber (Solanum tuberosum L. cv. Snowden) tissue, and was labeled "WT" (Table 1). Colonized agar plugs, $4 \mathrm{~mm}$ in diameter, were transferred from the margin of an actively growing culture of each isolate, mycelium-side down, onto modified rye $B$ agar amended with 0.0 or $1.0 \mu \mathrm{g} / \mathrm{ml}$ dimethomorph and incubated at $21^{\circ} \mathrm{C}$ in the dark with three replicate plates per concentration. The dimethomorph concentration used for selection was previously found to be highly inhibitory, yet sublethal for all isolates of $P$. infestans examined (24). Final colony diameter (FCD) was measured after 11 days. Isolates grown on control $(0.0 \mu \mathrm{g} / \mathrm{ml})$ 
and dimethomorph-amended medium (1.0 $\mu \mathrm{g} / \mathrm{ml})$ were labeled "CT" and "DM", respectively. One plate from each treatment was then used to subculture the isolate onto medium amended with the same concentration of dimethomorph, for a total of 10 subcultures. Portions of the colony were chosen for subculturing in an attempt to retain the wild-type colony phenotype of each isolate, while selecting sectors with higher growth rates. In the absence of markedly accelerated growth, plugs were chosen randomly from the margin of the colony. The rate of colony growth $(\mathrm{mm} /$ day) for each replicate plate was calculated for each cycle number and normalized relative to the mean rate of growth for the control plates of that cycle number. The rates of colony growth were analyzed as described below. Following the tenth each of the dimethomorph-exposed and control colonies, as described below.

Resistance generation: mutagenesis. Wild-type isolates of $P$. infestans (Table 1) for mutagenesis were grown on modified rye $\mathrm{B}$ agar at $21^{\circ} \mathrm{C}$ until the medium became completely colonized. Plates were flooded with $5.0 \mathrm{ml}$ of a $1-\mu \mathrm{g} / \mathrm{ml}$ ethidium bromide (EtBr) solution (in sterile $\mathrm{dH}_{2} \mathrm{O}$ ) and allowed to dry in a biological hood for $45 \mathrm{~min}$ with the lids removed. Cultures were then exposed to 254-nm UV light $\left(2.03 \mathrm{~W} / \mathrm{m}^{2}\right)$ for $5 \mathrm{~min}$. From each isolate, four 4-mm-diameter colonized agar plugs were transferred to rye $\mathrm{B}$ agar amended with either 0.0 or $10.0 \mu \mathrm{g} / \mathrm{ml}$ dimethomorph. Cultures not treated with EtBr/UV were also transferred onto control and dimethomorphamended rye B agar. Cultures were incubated in the dark at $21^{\circ} \mathrm{C}$ and examined at 7-day intervals for colony diameter and rapid growth or sectoring on the dimethomorph-amended medium. After 14 days, the fastest growing sector of each isolate from the fungicide-amended medium was used for further assays, and hereafter labeled "MU". The $\mathrm{EC}_{50}$ was calculated for each as described below. subculture, the $\mathrm{EC}_{50}$ was calculated for

Calculation of $\mathrm{EC}_{50}$ values and statistical analysis. To determine if the rate of growth for an isolate repeatedly cultured on dimethomorph-amended rye $\mathrm{B}$ agar increased significantly with culture number, the growth rates (mm/day) were analyzed with an analysis of variance calculated as a multifactorial, completely randomized design (Proc MIXED, SAS/Stat, SAS Institute, Cary, NC), with isolate, cycle number, and dimethomorph concentration in the medium as the main effects. Means were separated by Fisher's least significant difference (LSD) at $P=0.05$.

The in vitro sensitivity of $P$. infestans isolates to dimethomorph was determined as described previously without modification (24). In summary, each isolate was cultured in triplicate on rye B agar amended with $0.0,0.1,1.0$, or $10.0 \mu \mathrm{g}$ of dimethomorph per ml. FCD was measured after 11 days, and the percent inhibition relative to the mean of the control plates was calculated for each concentration. Percent inhibition values were then transformed using probits and linearly regressed on the $\log _{10}$ of concentration (9). The $\mathrm{EC}_{50}$ for hyphal growth (diameter) was calculated based on regression parameter estimates (SigmaPlot, SPSS Inc., Chicago, IL) and back-transformed. Resistance factors were calculated as the ratio of the $\mathrm{EC}_{50}$ for the dimethomorph-exposed, control, or $\mathrm{EtBr} / \mathrm{UV}$ treated cultures of an isolate to the $\mathrm{EC}_{50}$ of the wild-type. The assay was repeated three times, and the calculated $\mathrm{EC}_{50}$ values for each isolate were used as replicate blocks in an analysis of variance calculated as a randomized complete block design (Proc MIXED, SAS/Stat). Means were separated by Fisher's least significant difference (LSD) at $P=0.05$.

Virulence assays. Virulence, as defined by the frequency of successful infection of foliar disks or whole tubers, was assessed by removing fully expanded leaflets of similar age (main stem, leaf positions 10 to 12 above the soil line) from greenhousegrown potato plants (cv. Snowden). Leaflets were surface-disinfested in $0.5 \%$ so-

Table 1. Phytophthora infestans isolate identification, year isolated, mating type, allozyme-based genotype, physiological race, and state in which isolated

\begin{tabular}{lccccc}
\hline Isolate & $\begin{array}{c}\text { Year } \\
\text { isolated }\end{array}$ & Mating type & Genotype $^{\mathbf{x}}$ & $\begin{array}{c}\text { Physiological } \\
\text { race }^{\mathbf{y}}\end{array}$ & Origin $^{\mathbf{z}}$ \\
\hline Pi88 & 1995 & A1 & US1 & 3.6 .7 .10 .11 & ND \\
Pi95-5 & 1995 & A1 & US1 & 1.2 .3 .7 .9 & MI \\
Pi458 & 1998 & A1 & US17 & 1.2 .3 .4 .5 .6 .7 .9 .11 & ID \\
Pi670 & 1997 & A2 & US7 & 1.2 .3 .4 .5 .6 .10 .11 & OR \\
Pi671 & 1997 & A2 & US14 & 1.10 & WA \\
Pi213 & 1997 & A2 & US8 & 1.2 .3 .4 .5 .6 .7 .10 .11 & CO \\
Pi94-4 & 1994 & A2 & US8 & 1.3 .5 & MI \\
Pi95-7 & 1995 & A2 & US8 & 1.2 .3 .4 .5 .6 .7 .10 .11 & MI \\
Pi97-2 & 1997 & A2 & US8 & 1.3 .4 .5 .8 .11 & MI \\
Pi98-1 & 1998 & A2 & US8 & 2.5 .6 .7 .8 .9 .10 .11 & MI \\
Pi98-2 & 1998 & A2 & US8 & 1.2 .3 .4 .5 .7 .10 .11 & MI \\
\hline
\end{tabular}

${ }^{\mathrm{x}}$ Based on allozyme banding patterns and mating type as described by Goodwin et al. (11).

${ }^{y}$ Determined using inoculations onto potato lines with different R-genes as described by Al-Kherb et al. (3).

${ }^{\mathrm{z}}$ State of origin (United States). All isolates were obtained from single lesions on potato foliage. dium hypochlorite in $\mathrm{dH}_{2} \mathrm{O}(10 \%$ commercial bleach solution) for $1 \mathrm{~min}$, rinsed three times in $\mathrm{sdH}_{2} \mathrm{O}$, allowed to dry, and cut into 20-mm-diameter leaf disks with a sterilized cork borer. Leaf disks were randomly assigned to treatments and placed on water agar $(15.0 \mathrm{~g} / \mathrm{liter})$ amended with rifamycin ( $37.5 \mathrm{mg} /$ liter), ampicillin (10 $\mathrm{mg} / \mathrm{liter})$, and nystatin $(37.5 \mathrm{mg} / \mathrm{liter})$. Sporangia/zoospore suspensions were prepared as previously described (24) for a final concentration of $1.0 \times 10^{4}$ sporangia per $\mathrm{ml}$. The sporangia/zoospore suspension from each isolate was applied to four leaf disks per replicate $(50 \mu \mathrm{l} / \mathrm{disk})$, with three replicates. The experiment was repeated twice. Inoculated leaf disks were incubated at $21^{\circ} \mathrm{C}$ light $/ 18^{\circ} \mathrm{C}$ dark (12-h cycles) and examined with a dissecting microscope at $96 \mathrm{~h}$ after inoculation for symptoms and signs of infection by $P$. infestans, such as the formation of typical late blight lesions and sporulation. Pathogen identity was confirmed microscopically. Leaf disk inoculations were not performed with $\mathrm{EtBr} / \mathrm{UV}$-treated isolates, as sporulation was absent or highly disrupted for all isolates. An analysis of variance on the incidence of diseased leaf disks was performed as previously described.

Pathogen-free potato tubers (cv. Snowden) with an average diameter of $5 \mathrm{~cm}$ were surface-disinfested as before. Colonized portions of rye $\mathrm{B}$ agar, $1 \mathrm{~cm}^{2}$, were excised from the margin of an actively growing colony of $P$. infestans and placed into a sterile 1-cc syringe with an $181 / 2$ gauge needle. A wound approximately 1 $\mathrm{cm}$ from the apex of the tuber and $0.5 \mathrm{~cm}$ deep into the tissue was created by stabbing the tuber with a pair of flamesterilized forceps. Three tubers per replicate were inoculated by extruding approximately $0.1 \mathrm{ml}$ of macerated colonized agar through the needle into the wound and placed into a covered plastic container. There were three replicates per run, and the experiment was repeated twice. The tubers were incubated in the dark for 7 days at $18^{\circ} \mathrm{C}$, and tuber surface and crosssections were evaluated for symptoms and signs of infection by $P$. infestans. Pathogen presence was verified as before when applicable. Tuber inoculations were not performed on $\mathrm{EtBr} / \mathrm{UV}$-treated isolates. An analysis of variance on the incidence of tuber infection was performed as previously described.

\section{RESULTS}

Mycelial selection. Relative to the control (CT), the rate of growth for all isolates on medium amended with dimethomorph at $1.0 \mu \mathrm{g} / \mathrm{ml}$ (SL) increased with subculture number for all isolates, e.g., Pi671 (Fig. 1). With most isolates, the largest increase occurred between the initial and second subcultures, whereas changes at subsequent subcultures were generally smaller or absent. At the end of the tenth 
subculture, the FCD of each DM isolate was from 1.7- to 5.5-fold larger than the FCD following the initial subculture.

The $\mathrm{EC}_{50}$ values for the WT and CT of any isolate were not significantly different (Table 2). Isolates Pi458, Pi670, Pi94-4, and Pi98-1 had significantly higher $\mathrm{EC}_{50}$ values for the DM than for WT or CT. For all isolates, except Pi98-2, the calculated resistance factor (RF) was numerically larger for the DM than for the CT. Of the four isolates with significantly different $\mathrm{EC}_{50}$ values, Pi94-4 had the largest RF value (6.45). However, the isolate with the largest RF, Pi95-5 (7.48), did not have significantly different $\mathrm{EC}_{50}$ values between DM and WT.

The ability to infect and cause symptoms on potato leaf disks was limited for most isolates examined, regardless of treatment, as only four of $11 \mathrm{WT}$ isolates resulted in $75 \%$ or more leaf disks infected (Table 3). The WT of isolates Pi95-5, Pi671, Pi670, Pi94-4, Pi97-2, and Pi98-2 successfully infected $50 \%$ or less of leaf disks, indicating low virulence, whereas only the WT of Pi458 infected all leaf disks. In comparison to the WT, the DM had significantly reduced virulence for six of 11 isolates of $P$. infestans. In contrast, only the CT of isolates Pi458 and Pi95-7 infected significantly fewer leaf disks than the WT.

Infection and symptom development in whole tubers following inoculation with mycelium was more efficient than leaf disk inoculation with the WT of eight of 11 isolates causing symptoms in all tubers inoculated (Table 3). The DM cultures of seven isolates infected significantly fewer tubers compared with the WT. Four of 11 isolates subcultured on control medium (CT) infected significantly fewer tubers when compared with the corresponding WT.

Mutagenesis. Following the mutagenesis treatment, all isolates grew on nonamended rye B agar, except Pi88 (data not

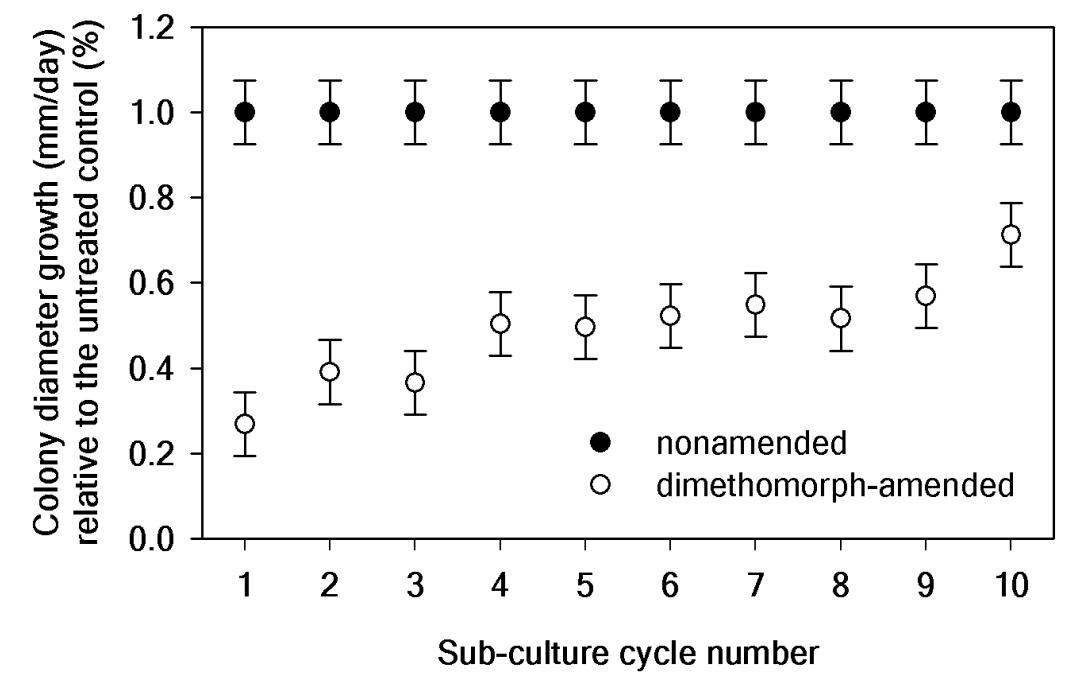

Fig. 1. Rates of colony growth (mm/day) for Phytophthora infestans isolate Pi671 on rye B agar amended with dimethomorph $(1.0 \mu \mathrm{g} / \mathrm{ml})$ relative to the rate of growth of the same isolate on nonamended medium. Error bars represent Fisher's LSD $(P=0.05)$.

Table 2. Calculated $\mathrm{EC}_{50} \mathrm{x}$ values and resistance factors for wild-type isolates of Phytophthora infestans and the same isolates repeatedly cultured on nonamended or dimethomorph-amended medium

\begin{tabular}{lccccccc}
\hline & \multicolumn{3}{c}{ EC $_{\mathbf{5 0}}$} & & \multicolumn{2}{c}{ Resistance factor $^{\mathbf{y}}$} \\
\cline { 2 - 3 } \cline { 6 - 7 } Isolate & $\mathbf{W T}^{\mathbf{z}}$ & $\mathbf{C T}$ & $\mathbf{D M}$ & & $\mathbf{C T}$ & $\mathbf{D M}$ \\
\hline Pi88 & $0.35 \mathrm{a}$ & $0.37 \mathrm{a}$ & $0.77 \mathrm{a}$ & & 1.07 & 2.22 \\
Pi95-5 & $0.11 \mathrm{a}$ & $0.19 \mathrm{a}$ & $0.80 \mathrm{a}$ & & 1.74 & 7.48 \\
Pi458 & $0.84 \mathrm{~b}$ & $0.56 \mathrm{~b}$ & $1.82 \mathrm{a}$ & & 0.66 & 2.16 \\
Pi670 & $0.62 \mathrm{~b}$ & $0.54 \mathrm{~b}$ & $1.49 \mathrm{a}$ & & 0.88 & 2.42 \\
Pi671 & $0.70 \mathrm{a}$ & $1.05 \mathrm{a}$ & $1.08 \mathrm{a}$ & & 1.49 & 1.54 \\
Pi213 & $0.68 \mathrm{a}$ & $0.87 \mathrm{a}$ & $0.98 \mathrm{a}$ & & 1.28 & 1.44 \\
Pi94-4 & $0.44 \mathrm{~b}$ & $0.86 \mathrm{~b}$ & $2.85 \mathrm{a}$ & & 1.96 & 6.45 \\
Pi95-7 & $0.61 \mathrm{a}$ & $0.62 \mathrm{a}$ & $0.74 \mathrm{a}$ & & 1.01 & 1.21 \\
Pi97-2 & $0.24 \mathrm{a}$ & $0.37 \mathrm{a}$ & $0.85 \mathrm{a}$ & & 1.56 & 3.59 \\
Pi98-1 & $0.56 \mathrm{~b}$ & $0.53 \mathrm{~b}$ & $1.65 \mathrm{a}$ & & 0.96 & 2.96 \\
Pi98-2 & $0.59 \mathrm{a}$ & $1.26 \mathrm{a}$ & $1.25 \mathrm{a}$ & & 2.14 & 2.13 \\
\hline
\end{tabular}

${ }^{x}$ Effective concentration to reduce colony diameter to $50 \%$ of $0.0 \mu \mathrm{g} / \mathrm{ml}$ dimethomorph-amended control. Means in a row followed by the same letter are not significantly different within each isolate using Fisher's LSD $(P=0.05)$. Comparisons between treatments of different isolates are not shown.

${ }^{\mathrm{y}}$ Resistance factor $=\mathrm{EC}_{50}$ of manipulated isolate/EC $\mathrm{EC}_{50}$ of WT. Resistance factor of WT not applicable.

${ }^{\mathrm{z}} \mathrm{WT}=$ wild-type. $\mathrm{CT}$ and $\mathrm{DM}=$ subcultured 10 times on medium amended with 0.0 or $1.0 \mu \mathrm{g} / \mathrm{ml}$ dimethomorph, respectively. shown). When cultured on nonamended medium, EtBr/UV-treated cultures exhibited disrupted colony morphology and slower growth rates compared with nonexposed cultures (data not shown). Of the isolates that grew following the mutagenesis treatment, only Pi458 and Pi98-2 failed to grow on medium amended with 10.0 $\mu \mathrm{g} / \mathrm{ml}$ dimethomorph. However, most isolates required more than 14 days to develop sufficient growth for subculturing. Sectors with increased growth rates on dimethomorph-amended medium were common, but not always present. The $\mathrm{EtBr} / \mathrm{UV}$-treated colonies from all isolates had significantly higher $\mathrm{EC}_{50}$ values than did the corresponding WT (Table 4). The EtBr/UV-treated colony of isolate Pi94-4 had the highest $\mathrm{EC}_{50}$ value $(9.92 \mu \mathrm{g} / \mathrm{ml})$, and those of isolates Pi95-5 and Pi94-4 had the largest RF values at 23.17 and 22.45 , respectively.

\section{DISCUSSION}

A significant decrease in sensitivity to dimethomorph (increase in the $\mathrm{EC}_{50}$ for in vitro growth) was demonstrated in $P$. infestans following repeated subculturing on medium amended with a sublethal concentration of dimethomorph in four of the 11 $P$. infestans isolates examined. Almost all isolates had a numerically increased $\mathrm{EC}_{50}$ for the dimethomorph-treated cultures compared with the WT. However, the resistance factor for most isolates was $<3$, which represents a relatively small change. The rapid increase in final colony diameter by the third subculture cycle on amended medium indicates a physiological adaptation to dimethomorph or selection for a mutation providing resistance. Culturing the isolates on nonamended medium prior to in vitro growth sensitivity assessments for $\mathrm{EC}_{50}$ calculation was employed to reduce the effects of physiological adaptation.

The development of resistance to dimethomorph was demonstrated in $P$. infestans following the EtBr/UV exposure of mycelium and resulted in two $P$. infestans isolates with resistance factor values $>20$. These values were similar to previously reported RF values for dimethomorph generated for $P$. parasitica using UV irradiation (6) and for P. capsici using chemical mutagenesis (26). In comparison, the resulting RF of $P$. capsici for the phenylamide fungicide metalaxyl was $>100$ in the latter study, and an RF value of 20 for dimethomorph was considered moderate. All isolates of $P$. infestans that survived the mutagenesis treatment had reduced growth rates on nonamended medium and disrupted colony morphology compared with the wild-type. On nonamended medium, both factors could be attributable to mutations unrelated to dimethomorph resistance negatively affecting growth or the dimethomorph resistance mechanism(s) itself. Particularly in the former situation, 
one might have expected additional fitness reductions, including virulence, as mutations generally reduce the fitness of Phytophthora isolates (18). The loss of ability to sporulate supports this hypothesis.

The $\mathrm{EC}_{50}$ value derived from in vitro colony growth, while commonly used in fungicide sensitivity studies $(9,13,26)$, is sensitive to changes in the growth rate of the fungus because of the percent inhibition transformation relative to the control. A mutant isolate with a reduced growth rate may have the same colony diameter as the wild-type at nonlethal concentrations of the fungicide, and yet the smaller colony diameter on nonamended medium results in a lower percent inhibition due to the reduced slope of the regression. Therefore, when calculating the $\mathrm{EC}_{50}$ value using percent inhibition versus concentration, a larger $\mathrm{EC}_{50}$ is calculated. Similarly, the $\mathrm{RF}$ value, being calculated using the $\mathrm{EC}_{50}$, is dependent on both reduced growth rates on nonamended medium and on extremely sensitive wild-type isolates. For example, the isolate Pi95-5 had reduced growth on nonamended medium for both repeated culturing on dimethomorph-amended medium and $\mathrm{EtBr} / \mathrm{UV}$-treated cultures and the lowest wild-type $\mathrm{EC}_{50}$ of any isolate. The DM-treated colony of this isolate had an $\mathrm{EC}_{50}$ that was not significantly different from either the WT or CT, and yet the isolate had the largest RF value.

The low frequency of infection by several WT isolates of $P$. infestans on leaf disks was not surprising because variable virulence has been documented, even on potato cultivars with no known R-genes (15). Possible reduction in efficiency of infection for the isolates subcultured on agar, regardless of fungicide amendment, was also expected, as P. infestans is known to lose virulence following long-term culturing in vitro (8). However, since the CT cultures of most isolates retained near-WT virulence, reduction in virulence of the DM cultures may have been associated with dimethomorph resistance. P. infestans requires the formation of viable sporangia for infection of foliar tissue, and any putative changes in cell wall formation resulting from the development of dimethomorph resistance or adaptation might disrupt sporangia formation. Additionally, cell wall components of $P$. infestans are known to induce resistance in potato (10), and it is possible that changes that occurred as a result of dimethomorph resistance allowed for the release of such compounds. Without detailed investigation of cell wall composition and formation, it is difficult to discern the true cause, and this phenomenon should be investigated further. In addition, excluding the chemical composition, little is known about the biochemistry involved with cell wall formation in Phytophthora (4), and therefore the genetic basis for resistance to dimethomorph may be difficult to discern.
The tuber inoculation test, while not cumvention of the periderm, was performed because differences in foliar and tuber susceptibility have been noted and may be important $(14,25)$. The lack of correlation between foliar and tuber inoculations was probably related to differences sporangia or zoospores for infection. Instead, it only required the pathogen to overcome any tuber defenses, and since the periderm was eliminated, the major tuber defense mechanism was absent. In situ foliar and tuber infection studies would be required to more fully evaluate this interaction.

The generation of resistance to dimethomorph in $P$. infestans was possible through both repeated selection on sublethal amended medium and chemical- or UV-induced mutation. The low amount of resistance that developed to dimethomorph, compared with previously published phenylamide resistance $(6,26)$, indicates that the mechanism may be biologically accurate because of the cirin the assays, in that the tuber inoculation did not require the development of viable

quantitative and possibly multigenic, as with the demethylation inhibitor fungicides commonly used to control true fungi (20). If this hypothesis is true, one would expect resistance in the field to develop through directional selection and occur in small increments (21). Also, resistance management techniques such as block treatments and co-application of dimethomorph with protectant fungicides would likely be effective. Currently, the development of field resistance to dimethomorph in P. infestans is unlikely for most potato-growing regions of the United States because growers rely primarily on protectant fungicide applications, and the use of systemic fungicides, including dimethomorph, typically is limited. However, as multisite fungicide usage is restricted because of the greater environmental impact, dimethomorph usage becomes more likely. Additionally, dimethomorph is being studied for the control of other Oomycete plant pathogens (17), and active resistance management strategies should be developed and implemented where appropriate.

Table 3. Incidence of infection by Phytophthora infestans on potato leaf disks and tubers inoculated with wild-type isolates and the same isolates repeatedly subcultured on nonamended or dimethomorph-amended medium

\begin{tabular}{|c|c|c|c|c|c|c|}
\hline \multirow[b]{2}{*}{ Isolate } & \multicolumn{3}{|c|}{ Leaf disks $(\%)^{y}$} & \multicolumn{3}{|c|}{ Whole tubers (\%) } \\
\hline & $\mathbf{W T}^{\mathbf{z}}$ & CT & DM & WT & CT & DM \\
\hline Pi88 & $58 \mathrm{a}$ & $50 \mathrm{a}$ & $58 \mathrm{a}$ & $100 \mathrm{a}$ & $33 b$ & $22 \mathrm{~b}$ \\
\hline Pi95-5 & $25 \mathrm{a}$ & $8 \mathrm{a}$ & $25 \mathrm{a}$ & $33 \mathrm{a}$ & $22 \mathrm{a}$ & $0 \mathrm{~b}$ \\
\hline Pi458 & $100 \mathrm{a}$ & $8 \mathrm{~b}$ & $25 \mathrm{~b}$ & $100 \mathrm{a}$ & $89 a$ & $44 \mathrm{~b}$ \\
\hline Pi670 & $50 \mathrm{a}$ & $50 \mathrm{a}$ & $33 a$ & $100 \mathrm{a}$ & $67 \mathrm{~b}$ & $22 \mathrm{c}$ \\
\hline Pi671 & $50 \mathrm{a}$ & $50 \mathrm{a}$ & $17 \mathrm{~b}$ & $100 \mathrm{a}$ & $100 \mathrm{a}$ & $100 \mathrm{a}$ \\
\hline Pi213 & $92 \mathrm{a}$ & $75 a$ & $25 \mathrm{~b}$ & $100 \mathrm{a}$ & $100 \mathrm{a}$ & $100 \mathrm{a}$ \\
\hline Pi94-4 & $42 \mathrm{a}$ & $17 \mathrm{ab}$ & $8 \mathrm{~b}$ & $56 \mathrm{a}$ & $56 a$ & $44 \mathrm{a}$ \\
\hline Pi95-7 & $92 \mathrm{a}$ & $58 \mathrm{~b}$ & $42 \mathrm{~b}$ & $100 \mathrm{a}$ & $78 \mathrm{~b}$ & $44 \mathrm{c}$ \\
\hline Pi97-2 & $17 \mathrm{a}$ & $17 \mathrm{a}$ & $25 \mathrm{a}$ & $67 \mathrm{a}$ & $67 \mathrm{a}$ & $22 \mathrm{~b}$ \\
\hline Pi98-1 & $92 \mathrm{a}$ & $75 \mathrm{a}$ & $8 \mathrm{~b}$ & $100 \mathrm{a}$ & $56 \mathrm{~b}$ & $33 \mathrm{c}$ \\
\hline Pi98-2 & $42 \mathrm{a}$ & $33 \mathrm{a}$ & $33 a$ & $100 \mathrm{a}$ & $100 \mathrm{a}$ & $89 a$ \\
\hline
\end{tabular}

y Determined using the percentage of leaf disks (out of four) or tubers (out of three) with symptoms and signs of infection by $P$. infestans. Leaf disks and tubers checked for infection at 96 and $168 \mathrm{~h}$ after inoculation, respectively. Means in a row followed by the same letter are not significantly different within each isolate using Fisher's LSD $(P=0.05)$. Comparisons between treatments of different isolates not shown.

${ }^{\mathrm{z}} \mathrm{WT}=$ wild-type. $\mathrm{CT}$ and $\mathrm{DM}=$ subcultured 10 times on medium amended with 0.0 or $1.0 \mu \mathrm{g} / \mathrm{ml}$ dimethomorph, respectively.

Table 4. The $\mathrm{EC}_{50}{ }^{\mathrm{x}}$ values and resistance factors for wild-type isolates of Phytophthora infestans and the same isolates following treatment with ethidium bromide (EtBr)/UV light

\begin{tabular}{lcccc}
\hline & \multicolumn{2}{c}{ EC $_{\mathbf{5 0}}$} & & Resistance factor $^{\mathbf{y}}$ \\
\cline { 2 - 3 } Isolate & WT $^{\mathbf{z}}$ & MU & MU \\
\hline Pi95-5 & $0.17 \mathrm{~b}$ & $2.48 \mathrm{a}$ & 23.17 \\
Pi670 & $0.62 \mathrm{~b}$ & $1.21 \mathrm{a}$ & 1.97 \\
Pi671 & $0.70 \mathrm{~b}$ & $2.29 \mathrm{a}$ & 3.26 \\
Pi213 & $0.68 \mathrm{~b}$ & $4.37 \mathrm{a}$ & 6.42 \\
Pi94-4 & $0.44 \mathrm{~b}$ & $9.92 \mathrm{a}$ & 22.45 \\
Pi95-7 & $0.61 \mathrm{~b}$ & $4.43 \mathrm{a}$ & 7.23 \\
Pi97-2 & $0.24 \mathrm{~b}$ & $1.24 \mathrm{a}$ & 5.22 \\
Pi98-1 & $0.56 \mathrm{~b}$ & $1.98 \mathrm{a}$ & 3.56 \\
\hline
\end{tabular}

${ }^{x}$ Effective concentration to reduce colony diameter to $50 \%$ of $0.0 \mu \mathrm{g} / \mathrm{ml} \mathrm{dimethomorph-amended}$ control. Means in a row followed by the same letter are not significantly different within each isolate using Fisher's LSD $(P=0.05)$. Comparisons between treatments of different isolates are not shown.

y Resistance factor $=\mathrm{EC}_{50}$ of manipulated isolate/EC ${ }_{50}$ of WT. Resistance factor of WT not applicable.

$\mathrm{z} \mathrm{WT}=$ wild-type. $\mathrm{MU}=$ treated with $\mathrm{EtBr} / \mathrm{UV}$ light. 


\section{ACKNOWLEDGMENTS}

This research was funded in part by BASF Corporation. Specials thanks to B. Dunlap and R. Schafer for technical assistance and F. Workneh for statistical consultation.

\section{LITERATURE CITED}

1. Albert, G., Curtze, J., and Drandarevski, C. A. 1988. Dimethomorph (CME 151), a novel curative fungicide. Proc. Brighton Crop Prot. Conf. - Pests Dis. 1:17-24.

2. Albert, G., Thomas, A., and Guhne, M. 1991. Fungicidal activity of dimethomorph on different stages in the life cycle of Phytophthora infestans and Plasmopara viticola. ANPP - Int. Conf. Plant Dis., 3rd. Bordeaux, FR.

3. Al-Kherb, S. M., Fininsa, C., Shattock, R. C., and Shaw, D. S. 1995. The inheritance of virulence of Phytophthora infestans to potato. Plant Pathol. 44:552-562.

4. Bartnicki-Garcia, S., and Wang, M. C. 1983. Biochemical aspects of morphogenesis in Phytophthora. Pages 121-137 in: Phytophthora. Its Biology, Taxonomy, Ecology, and Pathology. D. C. Erwin, S. Bartnicki-Garcia, and P. H. Tsao, eds. American Phytopathological Society, St. Paul, MN.

5. Caten, C. E., and Jinks, J. L. 1968. Spontaneous variability of single isolates of Phytophthora infestans. I. Cultural variations. Can. J. Bot. 46:329-348.

6. Chabane, K., Leroux, P., and Bompeix, G. 1993. Selection and characterization of Phytophthora parasitica mutants with ultravioletinduced resistance to dimethomorph or metalaxyl. Pestic. Sci. 39:325-329.

7. Eckert, J. W. 1988. Historical developments of fungicide resistance in plant pathogens. Pages 1-3 in: Fungicide Resistance in North America. C. J. Delp, ed. American Phytopathological Society, St. Paul, MN.

8. Erwin, D. C., and Ribeiro, O. K. 1996. Phy- tophthora Diseases Worldwide. American Phytopathological Society, St. Paul, MN.

9. Ferrin, D. M., and Kabashima, J. N. 1991. In vitro insensitivity to metalaxyl of isolates of Phytophthora citricola and $P$. parasitica from ornamental hosts in Southern California. Plant Dis. 75:1041-1044.

10. Friend, J. 1991. The biochemistry and cell biology of interaction. Pages 85-129 in: Advances in Plant Pathology. Phytophthora infestans, the Cause of Potato Late Blight. D. S. Ingram and P. H. Williams, eds. Academic Press Ltd., San Diego, CA.

11. Goodwin, S. B., Schneider, R. E., and Fry, W. E. 1995. Use of cellulose-acetate electrophoresis for rapid identification of allozyme genotypes of Phytophthora infestans. Plant Dis. 79:1181-1185.

12. Goodwin, S. B., Smart, C. D., Sandrock, R. W., Deahl, K. L., Punja, Z. K., and Fry, W. E. 1998. Genetic change within populations of Phytophthora infestans in the United States and Canada during 1994 to 1996: Role of migration and recombination. Phytopathology 88:939-949.

13. Kadish, D., and Cohen, Y. 1988. Estimation of metalaxyl resistance in Phytophthora infestans. Phytopathology 78:915-919.

14. Kirk, W. W., Felcher, K. J., Douches, D. S., Niemira, B. A., and Hammerschmidt, R. 2001. Susceptibility of potato (Solanum tuberosum L.) foliage and tubers to the US8 genotype of Phytophthora infestans. Am. J. Potato Res. 78:319-322.

15. Knutson, K. W., and Eide, C. J. 1961. Parasitic aggressiveness in Phytophthora infestans. Phytopathology 51:286-290.

16. Kuhn, P. J., Pitt, D., Lee, S. A., Wakley, G., and Sheppard, A. N. 1991. Effects of dimethomorph on the morphology and ultrastructure of Phytophthora. Mycol. Res. 95:333-340.
17. Matheron, M. E., and Porchas, M. 2002. Comparative ability of six fungicides to inhibit development of Phytophthora gummosis on citrus. Plant Dis. 86:687-690.

18. Mena, G. L., Munoz, C. I., Guzman, P. A., and Bailey, A. M. 1994. Variation in cutinase, esterase, and chromosome patterns in Nop mutants of a transformed pathogenic strain of Phy tophthora capsici. Phytopathology 84:502-508.

19. Russell, P. E. 1995. Fungicide resistance Occurrence and management. J. Agric. Sci. 124:317-323.

20. Scheinpflug, H. 1988. History of DMI fungicides and monitoring for resistance. Pages $77-$ 78 in: Fungicide Resistance in North America. C. J. Delp, ed. American Phytopathological Society, St. Paul, MN.

21. Scheinpflug, H. 1988. Resistance management strategies for using DMI fungicides. Pages 93 94 in: Fungicide Resistance in North America C. J. Delp, ed. American Phytopathological Society, St. Paul, MN.

22. Secor, G. A., and Gudmestad, N. C. 1999. Managing fungal diseases of potato. Can. J. Plant Pathol. 21:212-221.

23. Staub, T. 1991. Fungicide resistance - Practical experience with antiresistance strategies and the role of integrated use. Annu. Rev. Phytopathol. 29:421-442.

24. Stein, J. M., and Kirk, W. W. 2003. Variations in the sensitivity of Phytophthora infestans isolates from different genetic backgrounds to dimethomorph. Plant Dis. 87:1283-1289.

25. Stewart, H. E., Bradshaw, J. E., and Wastie, R L. 1994. Correlation between resistance to late blight in foliage and tubers in potato clones from parents of contrasting resistance. Potato Res. 37:429-434

26. Young, D. H., Spiewak, S. L., and Slawecki, R. A. 2001. Laboratory studies to assess the risk of development of resistance to zoxamide. Pest Manag. Sci. 57:1081-1087. 